\title{
Pelatihan Keselamatan dan Kesehatan Kerja pada Kelompok Nelayan di Kawasan Pesisir Desa Hila Kabupaten Maluku Tengah
}

\section{La Rakhmat Wabula*1, Endah Fitriasari², Syahfitrah Umamity³, Ira Sandi Tunny ${ }^{4}$}

\author{
1,2,3,4Program Studi Ilmu Keperawatan, STIKes Maluku Husada, Indonesia \\ *e-mail: $\underline{\text { la.rakhmat.wabula.stikesmh@gmail.com }}{ }^{1}{ }_{2}$ endahftiriasari1605@gmail.com $^{2}{ }_{\text {. }}$ \\ syahfitrah.umamity@gmail.com ${ }^{3}$, irasandi.99@gmail.com ${ }^{4}$
}

\begin{abstract}
Abstrak
Warga pesisir yang tinggal di Desa Hila sebagian besar bergantung pada laut. Sebagian besar bekerja sebagai nelayan dan sebagian lainnya bekerja sebagai petani. Desa Hila Kabupaten Maluku Tengah para nelayannya sering mengalami kecelakaan saat bekerja di laut. Terdapat banyak potensi rsiko yang dapat terjadi seperti kapal bocor, terluka saat menarikjala, kelebihan muatan, dan tenggelam. Oleh karena itu, perlu diadakan pelatihan keselamatan dan kesehatan kerja untuk memberikan pemahaman dan mendorong kesadaran para nelayan di Kawasan Pesisir Desa Hila Kabupaten Maluku Tengah. Untuk tata tertib para nelayan bisa lebih memperhatikan keselamatannya. Selain memberikan pelatihan, kegiatan ini juga dibarengi dengan pembentukan kader kesehatan nelayan. Hasil hasil pre test manunjukkan bahwa para peserta sebelum diberikan informasi atau penjelasan menunjukkan 42 orang dari peserta (100\%) memperoleh nilai mayoritas peserta memiliki nilai 40 sejumlah 23 orang (61\%). Pada post test terdapat 19 orang (50\%) yang memiliki nilai 70 dengan nilai tertinggi adalah 100 (menjawab soal 100\% benar) sejumlah 3 orang. Peningkatan pemahaman peserta mengindikasikan keberhasilan kegiatan pengabdian masyarakat yang telah dilakukan.
\end{abstract}

Kata kunci: Keselamatan dan Kesehatan Kerja, Kawasan Pesisir, Nelayan

\begin{abstract}
The coastal people who live in Hila Village are mostly dependent on the sea. Most of them work as fishermen and some work as farmers. Hila Village, Central Maluku Regency, fishermen often have accidents while working at sea. Many potential risks can occur such as a ship leaking, getting injured while pulling nets, overloading, and sinking. Therefore, it is necessary to hold occupational safety and health training to provide the understanding and encourage awareness of fishermen in the Coastal Area of Hila Village, Central Maluku Regency. For the rules of the fishermen can pay more attention to safety. In addition to providing training, this activity is also accompanied by the formation of fisherman health cadres. The results of the pre-test showed that the participants before being given information or explanations showed that 42 of the participants (100\%) scored the majority of the participants had a score of 40, 23 people (61\%). In the post-test, there were 19 people (50\%) who had a score of 70 with the highest score being 100 (answering the question 100\% correctly) a total of 3 people. Increased understanding of participants indicates the success of community service activities that have been carried out.
\end{abstract}

Keywords: Coastal Areas, Fishermen, Occupational Safety and Health

\section{PENDAHULUAN}

Desa Hila Kabupaten Maluku Tengah adalah salah satu desa yang berada di Provinsi Maluku yang didominasi oleh lautan dengan persentase 87\%. Oleh karena itu Desa Hila memiliki potensi besar sebagai kawasan pesisir dengan memberdayakan nelayan-nelayan di wilayah perairannya. Warga Desa Hila kebanyakan bergantung pada laut. Sebagian besar bermata pencaharian sebagai nelayan dan sebagian yang lain bekerja sebagai petani. Kawasan Desa Hila memiliki potensi perairan yang cukup baik, namun tingkat kecelakaan yang terjadi pada nelayan di wilayah pesisir Desa Hila, diketahui cukup sering terjadi. Berdasarkan survey langsung ke lokasi tersebut diketahui terdapat bahaya-bahaya pada proses penangkapan ikan yang dilakukan nelayan. Diantaranya tidak dilakukannya pengecekan kondisi kapal kecil secara berkala, para nelayan tidak menggunakan pelampung saat mencari ikan, dan seringkali kelebihan muatan baik dari segi jumlah maupun hasil tangkapannya. Hal-hal ini merupakan penyebab tenggelamnya kapal nelayan ketika ombak tinggi. Kecelakaan ini terjadi karena kurangnya kesadaran para 
nelayan terhadap bahaya-bahaya (hazard) yang ada disekitarnya.

Secara umum, bahaya merupakan sesuatu yang berpotensi dapat menimbulkan kerugian (Zurimi Suardi at al, 2020). Kerugian dapat berupa gangguan kesehatan atau cedera pada manusia (pekerja), hilangnya waktu kerja, kerusakan pada properti, area atau tempat kerja, produk atau kerusakan lingkungan sekitar, kerugian pada proses produksi ataupun kerusakan-kerusakan lainnya (Kusnanto et al., 2020). Manusia pada umumnya tidak peduli dengan lingkungan sekitarnya, tidak terkecuali pada lingkungan kerjanya (Syahri \& Fitria, 2018). Lingkungan kerja adalah segala yang berhubungan dengan lokasi kerja yang mencakup sarana dan prasarana kerja yang terdapat di sekeliling pekerja ketika pekerja sedang melaksanakan pekerjaannya yang akan ikut mempengaruhi hasil pekerjaan (Wika, 2021).

Penelitian Wabula et al., (2019) menyebutkan bahwa lingkungan kerja yang aman dapat membuat pekerja menjadi lebih nyaman menjalani pekerjaannya. Banyak sekali jenis-jenis pekerjaan yang ada, seluruh jenis pekerjaan tersebut harus mampu menjaga pekerja agar tetap selamat (Wabula, 2020). Hal ini diatur dalam Undang-Undang No. 1 Tahun 1970 tentang Keselamatan Kerja, bahwa "Setiap tenaga kerja berhak mendapatkan perlindungan atas keselamatannya dalam melakukan pekerjaan untuk kesejahteraan dan meningkatkan produksi serta produktivitas Nasional" (Wabula, 2020). Keselamatan dan kesehatan kerja adalah suatu upaya agar pekerja selalu dalam keadaan selamat dan sehat selama melakukan pekerjaannya di tempat kerja maupun sumber dan proses produksi dapat secara aman dan efisien dalam pemakaiannya (Mira Andika, Nurleny, Ria Desnita, Fitria Alisa, 2020). Adapun tujuan keselamatan dan kesehatan kerja yaitu melindungi tenaga kerja akan keselamatannya dalam melakukan pekerjaan untuk menjamin keselamatan pekerja ditempat kerja (Wabula \& Tunny, 2021), kegiatan produksi harus dilakukan pemeliharaan dan dipergunakan secara aman dan efisien (Ilmi et al., 2021).

Kelompok Nelayan Desa Hila terletak di Kabupaten Maluku Tengah. Kelompok nelayan ini terdiri dari nelayan-nelayan konvensional yang mencari ikan menggunakan jaring dan pompong (perahu kecil) sebagai alat tangkapnya. Mereka hanya mencari ikan untuk memenuhi kebutuhannya sehari-hari dan selebihnya di jual ke desa lainnya. Diketahui kelompok nelayan Desa Hila berdiri sendiri dan tidak tergabung dengan komunitas nelayan yang ada di Desa Hila. Berdasarkan wawancara singkat dengan Ketua Kelompok Nelayan Desa Hila diketahui mereka belum memiliki koperasi dan mitra usaha sehingga sulit untuk berkembang.

Masalah yang dihadapi saat ini adalah cukup seringnya terjadi kecelakaan ringan hingga berat pada nelayan di Desa Hila. Adapun kecelakaan-kecelakaan ringan yang sering terjadi adalah nelayan terluka saat menarik jaring, terjatuh di kapal kecil, kapal kecil yang dikendarai selama melaut bocor hingga kecelakaan berat seperti tenggelam ketika melaut. Hal inilah yang menjadi tujuan utama dalam kegiatan pengabdian masyarakat ini yakni memberikan pemahaman dan edukasi kepada nelayan di Desa Hila akan pentingnya Keselamatan dan Kesehatan Kerja selama melakukan pekerjaannya mencari ikan di laut.

\section{METODE}

Tahapan kegiatan mulai awal sampai kahir kegiatan pengabdian terdiri dari beberapa tahap. Kegiatan ini diawali dengan survei tempat pengabdian, pembuatan proposal, koordinasi dengan mitra, koordinasi dengan puskesmas, dinas kesehatan, kemudian menentukan target mitra, tim memulai pengabdian. Pada awal pengabdian tim mengkaji data kebutuhan masyarakat dengan Forum Group Discussion (FGD), kemudian merancang model. Selanjutnya setelah mendapatkan pendanaan maka mengadakan pelatihan pada masyarakat dan kelompok terget, mengevaluasi kegiatan, membuat laporan dan presentasi hasil kegiatan.

Melalui kegiatan pengabdian masyarakat ini dicarikan solusi bagi permasalahanpermasalahan yang telah dirumuskan di atas. Pendekatan yang ditawarkan bagi realisasi program pengabdian masyarakat ini adalah model pemberdayaan dengan langkah-langkah yang telah dilakukan sebagai berikut: 
a. Tahap I adalah melakukan pre test dengan mengisi beberapa kuesioner yang dipandu oleh petugas (dosen dan mahasiswa) untuk menilai pengetahuan peserta mengenai Keselamatan dan Kesehatan Kerja nelayan saat melaut.

b. Tahap II adalah pengenalan Keselamatan dan Kesehatan Kerja pada nelayan saat melaut: penggunaan Alat Pelindung Diri saat melaut. Pada tahap ini dilakukan ceramah, tanya jawab dan diskusi. Media yang digunakan adalah leaflet, LCD, dan Laptop.

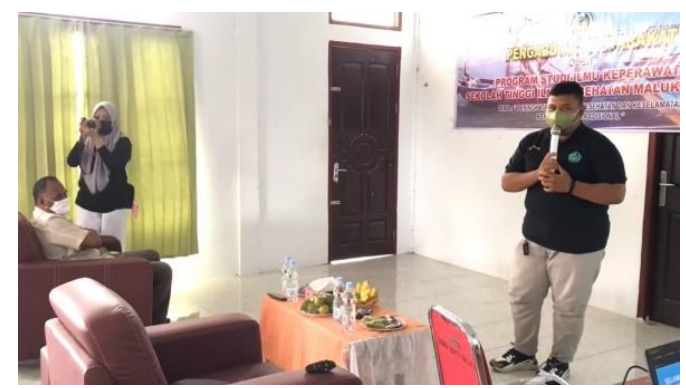

Gambar 1. Edukasi Kesehatan tentang Pentingnya Penggunaan APD

Tahap II adalah pelatihan pemberian Bantuan Hidup Dasar. Alat peraga yang digunakan adalah video dan peragaan gerakan oleh mahasiswa Program Studi Ilmu Keperawatan STIKes Maluku Husada. Mengajarkan Pemberian Bantuan Hidup Dasar sesuai dengan standar operasional prosedur.

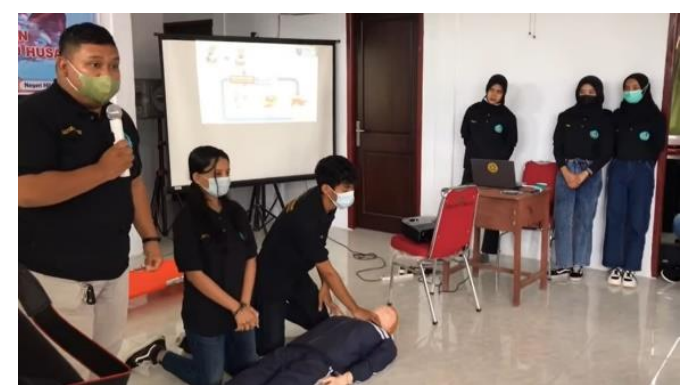

Gambar 2. Pelatihan Pemberian Hidup Dasar

c. Tahap III adalah pelatihan pemberian Balut Bidai. Alat peraga yang digunakan adalah video dan peragaan oleh mahasiswa Program Studi Ilmu Keperawatan STIKes Maluku Husada. Mengajarkan Pemberian pemberian Balut Bidai sesuai dengan standar operasional prosedur.

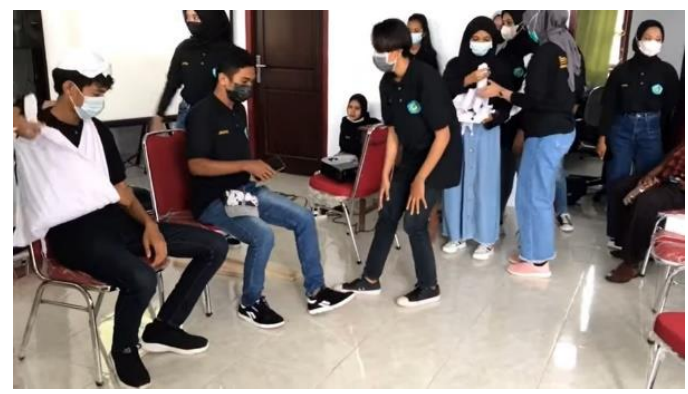

Gambar 3. Pelatihan Balut Bidai

c. Tahap IV adalah post test. Evaluasi dilakukan selama proses pelatihan dan follow up sesudah pelatihan selesai. Selama pelatihan, post test dilakukan dengan mengukur tingkat pengetahuan peserta dengan soal tentang Keselamatan dan Kesehatan Kerja pada Nelayan saat melaut sebanyak 10 pertanyaan. Soal diberikan sesudah diberikan edukasi kesehatan tentang Keselamatan dan Kesehatan Kerja pada Nelayan saat melaut. Evaluasi selama proses juga dilakukan untuk pelatihan Keselamatan dan Kesehatan Kerja pada Nelayan yaitu dengan 
meminta 3 peserta secara acak untuk mengulang kembali gerakan pemberian Bantuan Hidup Dasar dan pemberian balut bidai.

\section{HASIL DAN PEMBAHASAN}

Pengabdian pada masyarakat ini dilakukan pada tanggal 21 Agustus 2021 bertempat di Desa Hila Kabupaten Maluku Tengah. Kegiatan ini diikuti oleh kelompok nelayan dan perangkat desa. Seluruh tahapan yang harus dilalui dilakukan pada awal tahap kegiatan. Pada tahap pertama tim pengabdian melakukan pemeriksaan kesehatan pada peserta yang meliputi pemeriksaan gula darah sewaktu, asam urat dan kolesterol. Setelah semua peserta dilakukan pemeriksaan kesehatan peserta diminta berkumpul di Balai Desa untuk diberikan Pelatihan Keselamatan dan Kesehatan Kerja pada Nelayan. Peserta meliputi Kelompok Nelayan di Desa Hila Kabupaten Maluku Tengah. Jumlah peserta sebanyak 38 orang.

Pemberian edukasi ini dilaksanakan dengan pemberian materi melalui ceramah dan diskusi serta pembagian leaflet. Proses evaluasi (pre test dan post test) pada seluruh peserta menggunakan lembar pernyataan yang harus diisi oleh peserta kegiatan. Soal pre dan post test tersebut untuk mengetahui pengetahuan nelayan tentang keselamatan dan kesehatan kerja saat melaut yaitu pentingnya penggunaan alat pelindung diri saat melaut.

Berdasarkan tabel 1 dapat dilihat bahwa hasil pre test 10 pertanyaan para peserta sebelum diberikan informasi atau penjelasan menunjukkan 42 orang dari peserta $(100 \%)$ memperoleh nilai mayoritas peserta memiliki nilai 40 sejumlah 23 orang (61\%). Tabel 2 menunjukan bahwa pada post test terdapat 19 orang (50\%) yang memiliki nilai 70 dengan nilai tertinggi adalah 100 (menjawab soal 100\% benar) sejumlah 3 orang.

Tabel 1. Hasil Pre Test dan Post Test Pengetahuan Nelayan tentang Keselamatan dan Kesehatan Kerja pada Nelayan

\begin{tabular}{cccccc}
\hline Nilai Pre Test & Jumlah & $\mathbf{\%}$ & Nilai Pre Test & Jumlah & $\%$ \\
\hline 40 & 23 & 61 & 40 & 0 & 0 \\
50 & 10 & 26 & 50 & 4 & 10 \\
60 & 5 & 13 & 60 & 10 & 26 \\
70 & 0 & 0 & 70 & 19 & 50 \\
80 & 0 & 0 & 80 & 1 & 3 \\
90 & 0 & 0 & 90 & 1 & 3 \\
100 & 0 & 0 & 100 & 3 & 8 \\
Total & $\mathbf{3 8}$ & $\mathbf{1 0 0}$ & Total & $\mathbf{3 8}$ & $\mathbf{1 0 0}$ \\
\hline
\end{tabular}

Sumber: Data Primer 2021

Tabel 1 menunjukan bahwa terjadi peningkatan pengetahuan yang signifikan. Hasil ini mendukung penelitian Wabula \& Tunny (2021) yang menyatakan bahwa penderita yang menerima intervensi edukasi menimbulkan perilaku yang lebih baik. Meningkatnya pengetahuan nelayan tersebut termasuk pengetahuan dan perilaku patuh terhadap penggunaan alat pelindung diri (Sirait \& Samura, 2021). Ketika nelayan menerima pembelajaran, maka nelayan akan memiliki kemampuan dan tahu bagaimana cara manajemen keselamatan dan kesehatan kerja (Kusnanto et al., 2020).

Pemahaman tentang manajemen keselamatan dan kesehatan kerja untuk menurunkan angka kecelakaan kerja saat melaut (Purwangka et al., 2019). Maka dari itu pengetahuan nelayan tentang manajemen keselamatan dan kesehatan kerja harus ditekankan karena faktor ketidakpatuhan dan ketidakpahaman pangkal menuju kecelakaan kerja (Keswara, 2019).

Menurut Prabawati et al (2021) metode penyuluhan merupakan salah satu faktor yang mempengaruhi tercapainya suatu hasil penyuluhan secara optimal. Dalam penyuluhan kesehatan metode ceramah lebih efektif digunakan untuk membina perilaku baru atau seseorang yang telah mulai tertarik pada suatu perubahan perilaku atau inovasi. 


\section{KESIMPULAN}

Dari hasil penyuluhan dan pelatihan yang didapatkan bahwa sebagian peserta sudah mengetahui keselamatan dan kesehatan kerja pada nelayan. Kegiatan berjalan dengan baik, peserta aktif selama kegiatan berlangsung dan mendengarkan dengan seksama saat pemateri menyampaikan materi. Dampak dari kegiatan ini yaitu peserta sangat antusias dalam mengikuti kegiatan dan dapat mensimulasikan dengan baik mengenai cara pemberian bantuan hidup dasar dan melakukan balut bidai.

\section{DAFTAR PUSTAKA}

Ilmi, N., Mardiansyah, Y., \& Sari, D. I. (2021). Pelatihan Keselamatan dan Kesehatan Kerja (K3) Pada Kelompok Nelayan Teluk Mata Ikan, Kota Batam. Jurnal Sains Teknologi Dalam Pemberdayaan Masyarakat, 2(1), 9-16. https://doi.org/10.31599/jstpm.v2i1.623

Keswara. (2019). Pendidikan Kesehatan Terapi Komplementer Senam Kaki Diabetik Pada Lansia di Panti Sosial Lanjut Usia Tresna Werdha Natar, Lampung Selatan. Jurnal Kreativitas Pengabdian Kepada Masyarakat, 2(1), 101-104.

Kusnanto, K., Wabula, L. R., Purwanto, B., Arifin, H., \& Kurniawati, Y. (2020). Safety behaviour and healthy diving: A qualitative study in the traditional diverse fishermen. International Maritime Health, 71(1), 56-61. https://doi.org/10.5603/IMH.2020.0012

Mira Andika, Nurleny, Ria Desnita, Fitria Alisa, L. D. (2020). Jurnal Abdimas Saintika. Jurnal Abdimas Saintika, 2(2).

Prabawati, D., Sari, P., \& Neonbeni, Y. (2021). Pendidikan Kesehatan Tentang Perawatan Dan Senam Kaki Pada Pasien Diabetes. SELAPARANG Jurnal Pengabdian Masyarakat Berkemajuan, 4(3), 624-630. https://doi.org/10.31764/jpmb.v4i3.4775

Purwangka, F., Wisudo, S. H., Iskandar, B. H., \& Haluan, J. (2019). Model Pengelolaan Keselamatan Kerja Nelayan Di Palabuhanratu, Kabupaten Sukabumi. Jurnal IPTEKS Pemanfaatan Sumberdaya Perikanan, 5(9), 1-18. https://doi.org/10.20956/jipsp.v5i9.4312

Sirait, R. A., \& Samura, Z. A. P. (2021). Penyuluhan Kesehatan Tentang Penggunaan Alat Pelindung Diri Untuk Mencegah Penyakit Dermatitis Pada Nelayan. Jurnal Pengmas Kestra (Jpk), 1(1), 53-59. https://doi.org/10.35451/jpk.v1i1.720

Syahri, I. M., \& Fitria, M. (2018). Keselamatan Dan Kesehatan Kerja ( K3 ) Pada Nelayan Di Pos Upaya Kesehatan Kerja ( Pos Ukk) Puskesmas Belawan. TALENTA Conference Series: Tropical Medicine (TM), 1(1), 202-206.

Wabula, L. R. (2020). Perilaku Keselamatan dan Kesehatan Penyelaman pada Penyelam Tradisional Berbasis Health Action Process Aprroach. In CV. Cakra (I, Vol. 1, Issue 1). CV. Cakra. http://search.jamas.or.jp/link/ui/2008125856

Wabula, L. R., Kusnanto, K., \& Purwanto, B. (2019). Persepsi Risiko Keselamatan dan Kesehatan Menyelam pada Penyelam Tradisional dengan Kelumpuhan di Provinsi Maluku: Studi Kualitatif. Jurnal Penelitian Kesehatan "SUARA FORIKES" (Journal of Health Research "Forikes Voice"), 10(3), 184. https://doi.org/10.33846/sf10305

Wabula, L. R., \& Tunny, I. S. (2021). Sosialisasi Upaya Meningkatkan Perilaku Keselamatan Dan Kesehatan Kerja (K3) Pada Nelayan Tradisional Di Desa Kawa Kabupaten Seram Bagian Barat. Jurnal Pengabdian Masyarakat Indonesia, 1(6), 271-276.

Wika. (2021). Pengetahuan Sikap Dan Tindakan Menyangkut Kesehatan Dan Keselamatan Kerja Diantara Nelayan Penangkap Ikan Di Desa Likupang Dua Kecamatan Likupang Timur. Kesmas, 10(3), 131-139.

Zurimi Suardi at al. (2020). Peningkatan Pengetahuan dan Keterampilan melalui Penyuluhan dan Simulasi Bantuan Hidup Dasar pada Masyarakat Awam Pesisir di Dusun Kasuari Desa Asilulu Kecamatan Leihitu Kabupaten Maluku Tengah. PengabdianMu: Jurnal Ilmiah Pengabdian Kepada Masyarakat, 5(3), 264-269. 


\section{Halaman Ini Dikosongkan}

